\title{
Symptom, Adopting Healthy Life Style, and Quality of Life in Patients with Liver Cirrhosis: A Cross-Sectional Study
}

\author{
Myung Kyung Lee ( $\nabla$ mlee@knu.ac.kr) \\ Kyungpook National University https://orcid.org/0000-0002-2999-2299 \\ Woo Jin CHUNG \\ Keimyung University
}

Research

Keywords: symptom, exercise, diet, quality of life, liver cirrhosis

Posted Date: September 8th, 2020

DOI: https://doi.org/10.21203/rs.3.rs-68412/v1

License: (c) (i) This work is licensed under a Creative Commons Attribution 4.0 International License. Read Full License 


\section{Abstract}

Background: Previous studies have not considered a broad range of symptoms and the association with healthy behavior and quality of life of patients with liver cirrhosis.

Objectives: The purposes of the study were to examine the association of symptom with adopting exercise and consuming fruits and vegetables, and to identify factors associated with quality of life in patients with liver cirrhosis.

Methods: This cross-sectional study enrolled 91 consecutive patients with liver cirrhosis in one tertiary general hospital in South Korea between February 2016 and January 2017. Each study participant completed a self-administered questionnaire that measured symptom, stage-of-change in performing exercise and consumption of fruits and vegetables, and the Korean version of the 36-item Short-Form Health Survey. Multivariate logistic regression analysis and multiple regression models was used respectively to examine the association of each symptom with engaging in exercise and increasing consumption of fruits and vegetables and to evaluate factors affecting quality of life.

Results: Experiencing nausea was associated with increased intensity of exercise but experiencing shortness of breath was associated with decreased intensity of exercise. Experiencing right upper quadrant pain was associated with increased consumption of fruits and vegetables and muscle cramps, anorexia, right upper quadrant pain and body pain, itching, ascites or edema, bruising, and change in appearance negatively affected quality of life.

Conclusions: The results suggest that the types of symptoms experienced by a patient with liver cirrhosis hinder or promote the patient's adoption of exercise and dietary behavior. Experiencing symptoms may negatively affect quality of life. Caregivers should provide supportive care to patients with liver cirrhosis, which includes assessing and managing symptoms to improve quality of life.

\section{Background}

Deaths from viral hepatitis are much more due to progression to liver cirrhosis (LC) $(720,000$ deaths worldwide in 2015$)$ than hepatocellular carcinoma (470,000 deaths worldwide in 2015) [1]. As LC progresses, patients may experience progressive deterioration of liver function and accompanying signs and symptoms. Thus, most individuals with LC report multiple symptoms or complications [2] which can lead to a significant decline in QOL [3]. A better QOL is a predictor of survival in patients with LC [4], thus management of symptoms is critical for improving the QOL of patients with LC. Previous studies have examined the association between QOL and gastrointestinal symptoms, ascites, fatigue, and laboratory data $[3,5]$ in patients with LC, but did not consider the wide range of symptoms and complications that these patients experience. Indeed, even with self-reported data, it is not possible to fully understand LC patients' QOL.

Adopting healthy behaviors is a significant predictor of morbidity and survival in patients with LC [6], and it is generally known to improve the QOL of patients with chronic diseases [7]. The prevalence of deteriorating physical functioning is high and leads a poor prognosis in cirrhosis. In response to this, it is recommended to improve QOL in all patients with cirrhosis [8], particularly by performing regular exercise [9] and healthy eating [10].

Although exercising is known to improve QOL in LC patients, patients with LC are reported to have low levels of physical activity, with $76 \%$ of the time during day spent in a sedentary state [11]. Also, malnutrition is one of the most universal problems of LC, related with an increased risk of worsening disease progression and mortality [6]. Dietary guidelines for LC indicate that fruits and vegetables (F\&V) and whole grains, as well as certain types of proteins in appropriate quantities, are good foods for individuals with the condition [12]. Protein intake suggestions given in general guidelines cannot be applied to patients with LC because the protein intake of such patients should be carefully adjusted according to liver function, ascites, and blood ammonia levels [13]. On the other hand, the guideline for the intake of other foods such as F\&V can be suited to patients with chronic diseases. Regarding the adoption of a healthy diet, to our best knowledge, few studies to date have identified topics such as the adoption of an appropriate intake of $F \& V$ in patients with LC. Exploration of the relationship between symptom and adoption of healthy behaviors may provide basic information to devise appropriate strategies for promoting healthy behaviors in patients with a particular symptom.

Healthy behaviors, such as exercise and eating F\&V, are tied to the systemic symptoms experienced by LC patients, which conversely hinder the adoption of these behaviors. By determining that certain symptoms experienced by LC patients are correlated with adopting healthy behaviors, we can work to improve QOL of by controlling patients' subjective symptoms or encouraging the adoption of allied behaviors. The aims of the present study of a population with LC were to examine the association of symptom with engaging in exercise and with consuming F\&V and to examine factors influencing QOL.

\section{Materials \& Methods}


This study is using cross-sectional study design. The participants were sequentially recruited from one tertiary general hospital in South Korea between February 2016 and January 2017. Enrolled patients were over 19 years old, had diagnoses of LC within the previous 2 years, were undergoing regular treatments or follow-ups. Patients were excluded if they were not physically and mentally healthy enough to complete the questionnaires, or not able to understand the purpose of the study, or provide informed consent.

Of the patients returning to hospital for follow-up or treatment, we reviewed the hospital registries and initial assessments. From this review, we identified 98 patients as eligible, and 91 of them (95\%) accepted the informed consent document and completed the questionnaire. For the 7 individuals who refused, the most common reason for rejecting participation was "inconvenience". The G*Power 3.1.9.7 calculated sample size 84 which was based on these indices such as statistical analysis multiple regression, effect size $\mathrm{f}^{2} 0.21$ (Kim et al., 2006), type 1 error $5 \%$, power $80 \%$, and 9 predictors. Thus the final sample size 91 was acceptable.

Research staff contacted eligible patients at the ambulatory clinic and inpatient ward to explain the details of the study personally After providing informed consent, each participant was given a packet of questionnaires in quiet and independent meeting room and filled out the self-reported questionnaire in the presence of the research staff. The questionnaires collected information on sociodemographic characteristics, symptom, stage-of-change for adopting healthy behaviors based on the transtheoretical model (TTM) [14], and QOL. The study protocol conforms to the ethical guidelines of the 1975 Declaration of Helsinki as reflected in a priori approval by the affiliated Institutional Review Boards of the hospital (2015-09-020-003) and the university (2015-87).

\section{Measures}

\section{Symptom}

Multidimensional symptom was measured using a self-reported scale developed in a previous study [15]. This scale assesses 18 symptoms: fatigue, muscle cramps, decrease in memory, itching, dyspepsia, anorexia, dark urine, drowsiness, dry mouth, bruising, right upper quadrant (RUQ) pain, shortness of breath (SOB) and/or dyspnea, nausea and/or vomiting, body pain, urinary difficulty, tarry stools, ascites/edema, and change in appearance. The patient rated each item in frequency, intensity, and distress on a four-point Likert scale ( 0 : never experienced to 3: extremely experienced in frequency, intensity, and distress). The symptom score was calculated by summing the scores of frequency, intensity, and distress for each symptom. Thus, the score ranged from 0 to 162 , with a higher score indicating having experienced more severe symptoms. The Cronbach's alpha for the symptom scale in this study was 0.96 .

\section{Adopting Healthy Behaviors}

Adopting healthy behaviors was evaluated from the stage of change of TTM. The stage-of-change assessments for engaging in exercise and consumption of F\&V were adapted from previous study [16], in which the measure was developed from the TTM of behavior change [14]. These measures characterized differences in the stage-of-change of goal behaviors related to exercise and diet, from pre-adoption to adoption. The five items of each measure characterized participants into five stages: pre-contemplation, contemplation, preparation, action, and maintenance. Pre-contemplation describes an individual who is not engaged in a new behavior and has no intention of adopting the behavior in the near future. Contemplation indicates an individual who is not engaged in the behavior but is considering adopting the behavior in the next 6 months. Preparation describes an individual who has initiated some behavior changes, but the changes are not regular. Action describes an individual who is regularly engaged in the behavior, but only began this new behavior in the past 6 months. Maintenance indicates an individual who is regularly engaging in the behavior for more than 6 months.

Prior to questioning, exercise was defined as: "Brisk walking, cycling, swimming, mountain climbing, or another form of exercise that makes your heart pound, or makes you break out in a sweat, and is not part of your normal job activity"; F\&V servings was defined as "One serving of vegetables is equal to $1 / 2$ cup of cooked (or parboiled) vegetable, 1 cup raw vegetable or vegetable juice, and 2 cups leafy salad greens" and "one serving of fruits is 1 cup fruit or $1 / 2$ cup of fruit juice (orange juice, etc.) or $1 / 3$ cup of a fruit juice blend."

Participants were then asked: "On average, do you exercise regularly at least $30 \mathrm{~min}$ per day, 5 days a week and do you regularly eat at least five servings of F\&V per day [17]?" If a response was "Yes", the next questions were followed: "How long have you been exercising regularly at least 30 min per day, 5 days a week and regularly eating at least 5 servings of F\&V per day?" The responses were: "less than 6 months" (action stage) and "6 months or longer" (maintenance stage). If a patient replied as "No" or "I am not sure" to the initial question, they were asked the following question: "Have you initiated exercising at least 30 min per day, 5 days a week and eating at least 5 servings of F\&V per day?" The responses were: "Yes" (preparation stage) and "No". If the response was "No", the patient was asked following question: "Are you earnestly considering exercising at least 30 min per day, 5 days a week and eating at least 5 servings of $F \& V$ per day within the next 6 months?" The possible responses were: "Yes" (contemplation stage), "No", and "I am not sure" (pre-contemplation stage). The pre- 
contemplation, contemplation, and preparation were classified into "not engaging in exercise or consumption of F\&V", and action and maintenance were classified into "engaging in exercise or consumption of F\&V".

\section{QOL}

QOL was assessed using the validated Korean version of the Medical Outcomes Study 36-item Short-Form Health Survey (SF-36) [18]. This questionnaire has 36 items in 8 subscales: physical functioning, role limitations due to physical health problems, role limitations due to emotional problems, social functioning, body pain, general health, vitality, and mental health. The present study used 19 items in the 4 subscales: physical functioning, role limitations due to physical health problems, role limitations due to emotional problems, and social functioning. The score on each subscale ranged from 0 to 100, and a higher score indicated better functioning, but a higher score on role limitation indicated greater limitation. The internal consistency for the SF-36 was good (Cronbach's alpha $=0.85$ ). The usage of the questionnaire was approved by Optuminsight Life Sciences, Inc (Lincoln, RI, USA).

\section{Statistical Analysis}

Sociodemographic characteristics and degree of dimensional symptom were presented using descriptive statistics. First, univariate analyses, the independent-samples $t$-test was used to examine the associations of sociodemographic parameters with the total score of symptom, and the chi-square test was used to examine the associations of sociodemographic parameters with engaging in exercise and consumption of F\&V. For the chi-square test, we categorized the stages of pre-contemplation, contemplation, and preparation into "not performing exercise or consuming F\&V", and the stages of action and maintenance into "performing exercise and/or consuming F\&V". Then, multiple logistic regression analysis with stepwise selection was used to examine the independent effect of each symptom on engaging in exercise or consumption of $F \& V$, with control for age, sex, marital status, having a religion, job status, monthly income, residence area, and number of family members living together. For the logistic regression analyses, the 5 stages of change were classified into 2 categories: "not engaging in exercise or consumption of F\&V" (pre-contemplation, contemplation, and preparation) and "engaging in exercise or consumption of F\&V" (action and maintenance). The results were presented as adjusted odds ratio (aOR) with 95\% confidence interval (CI). Multiple regression analysis with stepwise selection, in which the main independent variables were engaging in exercise and consumption of $F \& V$, sociodemographic characteristics, and all subscales of symptom, was also used to identify the independent effect on QOL. These results are presented as beta coefficients and standard errors. All statistical analyses were conducted using SAS 9.4 package (SAS Institute, Cary, NC).

\section{Results}

\section{Characteristics of Participants}

A total of $56 \%$ of the 91 patients were male, the mean age was 59 years, and $70 \%$ of patients were less than 65 years (Table 1 ). Most participants were married and were covered by the national health insurance system (71.4\%). More than half of the patients had no job at the time of the questionnaire (59.3\%), two-thirds (65.9\%) lived in a metropolitan area, and about sixty percent were living with 2 or fewer family members. The mean of total symptom score of the participants was 33.6 [standard deviation (SD), 24.76] (Table 1). 
Table 1

Sociodemographic Characteristics of Participants \& Correlation of Sociodemographic Characteristics with Symptom, Performing Exercise, and Consumption of Fruits and Vegetables (F\&V).

\begin{tabular}{|c|c|c|c|c|c|c|c|c|c|}
\hline \multirow[t]{3}{*}{ Sociodemographic Characteristics } & \multirow[t]{3}{*}{$\mathrm{n}(\%)$} & \multirow{3}{*}{$\begin{array}{l}\text { Symptom } \\
\text { Mean } \\
\text { (SD) }\end{array}$} & \multirow[t]{3}{*}{$p$} & \multicolumn{2}{|c|}{ Performs exercise } & \multirow[t]{3}{*}{$p$} & \multicolumn{2}{|c|}{ Consumes F\&V } & \multirow[t]{3}{*}{$p$} \\
\hline & & & & no & yes & & no & yes & \\
\hline & & & & $\mathrm{n}(\%)$ & $\mathrm{n}(\%)$ & & $\mathrm{n}(\%)$ & $\mathrm{n}(\%)$ & \\
\hline \multicolumn{10}{|l|}{ Sex } \\
\hline Male & $\begin{array}{l}51 \\
(56.0)\end{array}$ & $\begin{array}{l}31.7 \\
(24.8)\end{array}$ & & $38(58.5)$ & $13(50.0)$ & 0.463 & $46(56.8)$ & $5(50.0)$ & \\
\hline Female & $\begin{array}{l}40 \\
(44.0)\end{array}$ & $\begin{array}{l}35.9 \\
(24.8)\end{array}$ & 0.427 & $27(41.5)$ & $13(50.0)$ & & $35(43.2)$ & $5(50.0)$ & 0.683 \\
\hline \multicolumn{10}{|l|}{ Age, years } \\
\hline$<65$ & $\begin{array}{l}64 \\
(70.3)\end{array}$ & $\begin{array}{l}33.1 \\
(23.7)\end{array}$ & & $45(69.2)$ & 19(73.1) & & $57(70.4)$ & $7(70.0)$ & \\
\hline$\geq 65$ & $\begin{array}{l}27 \\
(29.7)\end{array}$ & $\begin{array}{l}34.7 \\
(27.6)\end{array}$ & 0.788 & $20(30.8)$ & $7(26.9)$ & 0.717 & $24(29.6)$ & $3(30.0)$ & 0.981 \\
\hline \multicolumn{10}{|l|}{ Marital status } \\
\hline No spouse & $\begin{array}{l}26 \\
(28.6)\end{array}$ & $\begin{array}{l}37.5 \\
(26.0)\end{array}$ & & $21(32.3)$ & $5(19.2)$ & & $22(27.2)$ & $4(40.0)$ & \\
\hline With spouse & $\begin{array}{l}65 \\
(71.4)\end{array}$ & $\begin{array}{l}32.0 \\
(24.3)\end{array}$ & 0.343 & $44(67.7)$ & 21(80.8) & 0.212 & $59(72.8)$ & $6(60.0)$ & 0.397 \\
\hline \multicolumn{10}{|l|}{ Practice a religion } \\
\hline No & $\begin{array}{l}30 \\
(33.0)\end{array}$ & $\begin{array}{l}36.2 \\
(24.5)\end{array}$ & & 23(35.4) & $7(26.9)$ & & $26(32.1)$ & $4(40.0)$ & \\
\hline Yes & $\begin{array}{l}61 \\
(67.0)\end{array}$ & $\begin{array}{l}32.3 \\
(25.0)\end{array}$ & 0.483 & $42(64.6)$ & 19(73.1) & 0.438 & $55(67.9)$ & $6(60.0)$ & 0.616 \\
\hline \multicolumn{10}{|l|}{ Current job } \\
\hline No & $\begin{array}{l}54 \\
(59.3)\end{array}$ & $\begin{array}{l}40.0 \\
(27.7)\end{array}$ & & $40(61.5)$ & $14(53.8)$ & & $47(58.0)$ & $7(70.0)$ & \\
\hline Yes & $\begin{array}{l}37 \\
(40.7)\end{array}$ & $\begin{array}{l}24.2 \\
(15.9)\end{array}$ & 0.001 & $25(38.5)$ & $12(46.2)$ & 0.500 & $34(42.0)$ & $3(30.0)$ & 0.467 \\
\hline \multicolumn{10}{|l|}{ Monthly household income, \$ } \\
\hline$<2000$ & $\begin{array}{l}47 \\
(51.6)\end{array}$ & $\begin{array}{l}39.6 \\
(28.7)\end{array}$ & & $32(49.2)$ & $15(57.7)$ & & $39(48.1)$ & $2(20.0)$ & \\
\hline$\geq 2000$ & $\begin{array}{l}44 \\
(48.4)\end{array}$ & $\begin{array}{l}27.1 \\
(17.8)\end{array}$ & 0.014 & $33(50.8)$ & $11(42.3)$ & 0.466 & $42(51.9)$ & $8(80.0)$ & 0.049 \\
\hline \multicolumn{10}{|l|}{ Residence } \\
\hline City or town & $\begin{array}{l}31 \\
(34.1)\end{array}$ & $\begin{array}{l}36.0 \\
(25.2)\end{array}$ & & $20(30.8)$ & 11(42.3) & & $27(33.3)$ & $4(40.0)$ & \\
\hline Metropolitan & $\begin{array}{l}60 \\
(65.9)\end{array}$ & $\begin{array}{l}32.3 \\
(24.7)\end{array}$ & 0.510 & $45(69.2)$ & 15(57.7) & 0.294 & $54(66.7)$ & $6(60.0)$ & 0.675 \\
\hline \multicolumn{10}{|l|}{ National Health Service } \\
\hline Health insurance & $\begin{array}{l}65 \\
(71.4)\end{array}$ & $\begin{array}{l}30.2 \\
(21.8)\end{array}$ & & $47(72.3)$ & $18(69.2)$ & & $60(74.1)$ & $5(50.0)$ & \\
\hline Medical aid & $\begin{array}{l}26 \\
(28.6)\end{array}$ & $\begin{array}{l}42.1 \\
(29.8)\end{array}$ & 0.037 & $18(27.7)$ & $8(30.8)$ & 0.769 & $21(25.9)$ & $5(50.0)$ & 0.112 \\
\hline
\end{tabular}




\begin{tabular}{|c|c|c|c|c|c|c|c|c|c|}
\hline \multirow[t]{3}{*}{ Sociodemographic Characteristics } & \multirow[t]{3}{*}{$\mathrm{n}(\%)$} & \multirow{3}{*}{$\begin{array}{l}\text { Symptom } \\
\begin{array}{l}\text { Mean } \\
\text { (SD) }\end{array}\end{array}$} & \multirow[t]{3}{*}{$p$} & \multicolumn{2}{|c|}{ Performs exercise } & \multirow[t]{3}{*}{$p$} & \multicolumn{2}{|c|}{ Consumes F\&V } & \multirow[t]{3}{*}{$p$} \\
\hline & & & & no & yes & & no & yes & \\
\hline & & & & $\mathrm{n}(\%)$ & $\mathrm{n}(\%)$ & & n (\%) & $\mathrm{n}(\%)$ & \\
\hline \multicolumn{10}{|l|}{$\begin{array}{l}\text { Number of family members living } \\
\text { together }\end{array}$} \\
\hline$\leq 2$ & $\begin{array}{l}55 \\
(60.4)\end{array}$ & $\begin{array}{l}34.4 \\
(26.7)\end{array}$ & & $37(56.9)$ & 18(69.2) & & $49(60.5)$ & $6(60.0)$ & \\
\hline$\geq 3$ & $\begin{array}{l}36 \\
(39.6)\end{array}$ & $\begin{array}{l}32.4 \\
(21.9)\end{array}$ & 0.706 & $28(43.1)$ & $8(30.8)$ & 0.278 & $32(39.5)$ & $4(40.0)$ & 0.976 \\
\hline
\end{tabular}

\section{Overall Symptoms}

Analysis of the 18 symptoms indicated fatigue was the most-experienced symptom [mean $(M)=4.0, S D=2.5]$, followed by muscle cramps $(M=3.2, S D=2.4)$, decrease in memory $(M=2.7, S D=2.3)$, and itching $(M=2.4, S D=2.7)$ (Table 2). Analysis of symptom experiences significantly associated with QOL (please refer Table 4) indicated that anorexia was the sixth-most common symptom $(M=2.1, S D=2.5)$, bruising was tenth $(M=1.6, S D=2.1)$, RUQ pain was eleventh $(M=1.5, S D=2.1)$, body pain was fourteenth $(M=1.3, S D=2.0)$, ascites/edema was seventeenth $(M=1.0, S D=1.9)$, and change of appearance was the least experienced symptom $(M=0.9, S D=1.9)$ (Table 2). 
Table 4

Factors Independently Associated with Quality of Life.a

\begin{tabular}{|c|c|c|c|c|c|c|}
\hline Symptom & \multicolumn{2}{|c|}{ Performs exercise } & \multicolumn{4}{|c|}{ Consumes F\&V } \\
\hline \multicolumn{2}{|c|}{ Adjusted $^{\mathrm{a}}$ OR $(95 \% \mathrm{Cl})$} & \multirow[t]{2}{*}{$p$} & \multicolumn{2}{|c|}{$\begin{array}{l}\text { Adjusted }^{\mathrm{a}} \text { OR } \\
(95 \% \mathrm{Cl})\end{array}$} & \multirow[t]{2}{*}{$p$} & \multirow[b]{3}{*}{ NS } \\
\hline No & Yes & & No & Yes & & \\
\hline $\begin{array}{l}\text { Nausea and/or } \\
\text { vomiting }\end{array}$ & 1 (ref) & $\begin{array}{l}1.38 \\
(1.02- \\
1.86)\end{array}$ & 0.035 & & & \\
\hline $\begin{array}{l}\text { Shortness of } \\
\text { breath }\end{array}$ & 1 (ref) & $\begin{array}{l}0.58 \\
(0.39- \\
0.88)\end{array}$ & 0.010 & & & NS \\
\hline RUQ pain & & & NS & 1 (ref) & $\begin{array}{l}1.37 \\
(1.05- \\
1.79)\end{array}$ & 0.021 \\
\hline
\end{tabular}

Note. ${ }^{a}$ Adjusted for age, sex, marital status, practice a religion, job status, monthly household income, residence area, and the number of family members living together; OR, odds ratio; $\mathrm{Cl}$, confidence interval; RUQ, right upper quadrant

\begin{tabular}{|c|c|c|c|c|c|c|c|c|c|c|c|c|}
\hline \multirow[t]{2}{*}{ Factors } & \multicolumn{3}{|c|}{ Physical functioning } & \multicolumn{3}{|c|}{ Social functioning } & \multicolumn{3}{|c|}{$\begin{array}{l}\text { Role limitations due to } \\
\text { physical health problems }\end{array}$} & \multicolumn{3}{|c|}{$\begin{array}{l}\text { Role limitations due to } \\
\text { emotional problems }\end{array}$} \\
\hline & $\begin{array}{l}\text { Partial } \\
\mathrm{R}^{2}\end{array}$ & $\beta(\mathrm{se})$ & $p$ & $\begin{array}{l}\text { Partial } \\
\mathrm{R}^{2}\end{array}$ & $\beta(\mathrm{se})$ & $p$ & $\begin{array}{l}\text { Partial } \\
\mathrm{R}^{2}\end{array}$ & $\beta($ se) & $p$ & $\begin{array}{l}\text { Partial } \\
\mathbf{R}^{2}\end{array}$ & $\beta(\mathrm{se})$ & $p$ \\
\hline RUQ pain & 0.28 & $\begin{array}{l}-3.69 \\
(1.04)\end{array}$ & $<.0001$ & & & NS & & & NS & & & NS \\
\hline $\begin{array}{l}\text { Muscle } \\
\text { cramps }\end{array}$ & 0.12 & $\begin{array}{l}-4.29 \\
(0.90)\end{array}$ & $<.0001$ & & & NS & 0.24 & $\begin{array}{l}4.32 \\
(1.40)\end{array}$ & $<.0001$ & 0.26 & $\begin{array}{l}7.18 \\
(1.44)\end{array}$ & $<.0001$ \\
\hline Itching & 0.05 & $\begin{array}{l}-2.28 \\
(0.85)\end{array}$ & 0.006 & & & NS & & & NS & & & NS \\
\hline Ascites/edema & 0.03 & $\begin{array}{l}-2.98 \\
(1.13)\end{array}$ & 0.025 & & & NS & & & NS & & & NS \\
\hline Bruising & 0.03 & $\begin{array}{l}-2.44 \\
(1.01)\end{array}$ & 0.034 & & & NS & & & NS & & & NS \\
\hline Anorexia & 0.02 & $\begin{array}{l}-1.67 \\
(0.84)\end{array}$ & 0.049 & 0.03 & $\begin{array}{l}-1.58 \\
(0.73)\end{array}$ & 0.033 & 0.07 & $\begin{array}{l}4.42 \\
(1.27)\end{array}$ & 0.004 & & & NS \\
\hline $\begin{array}{l}\text { Change in } \\
\text { appearance }\end{array}$ & & & NS & & & NS & & & NS & 0.26 & $\begin{array}{l}5.25 \\
(1.84)\end{array}$ & 0.005 \\
\hline Bodily pain & & & NS & 0.43 & $\begin{array}{l}-5.55 \\
(0.91)\end{array}$ & $<.0001$ & & & NS & & & NS \\
\hline Being married & & & NS & & & NS & 0.06 & $\begin{array}{l}-19.86 \\
(6.76)\end{array}$ & 0.004 & & & NS \\
\hline Having a job & & & NS & 0.06 & $\begin{array}{l}10.30 \\
(3.42)\end{array}$ & 0.003 & & & NS & & & NS \\
\hline Model $\mathrm{R}^{2}$ & 0.53 & & & 0.52 & & & 0.37 & & & 0.52 & & \\
\hline
\end{tabular}

Note. ${ }^{\text {a }}$ The model included performing exercise and consumption of vegetables, sociodemographic characteristics, and all subscales of symptoms as the main independent variables. A higher score on functioning indicates better functioning, and a higher score on role limitation indicates more severe role limitations; se, standard error; RUQ, right upper quadrant; NS, not significant

\section{Correlations of Sociodemographic Characteristics with Symptom and Adoption of Healthy Behaviors}

Unemployment $(p=0.001)$, low monthly household income $(p=0.014)$, and joining Medical Aid, the national insurance for low-income individuals in South Korea $(p=0.037)$ were correlated with greater symptom. Greater monthly household income was correlated with higher 
consumption of $\mathrm{F} \& \mathrm{~V}(p=0.049)$ (Table 1$)$.

\section{Independent Associations of Symptom with Engaging in Exercise and Consumption of F\&V}

Multivariable analysis indicated that experiencing nausea and/or vomiting was associated with greater performance of exercise (aOR $=1.38$, $95 \% \mathrm{Cl}=1.02-1.86)$, but experiencing $\mathrm{SOB}$ was associated with less performance of exercise $(\mathrm{aOR}=0.58,95 \% \mathrm{Cl}=0.39-0.88)$. Experiencing RUQ pain was associated with greater consumption of $\mathrm{F} \& \mathrm{~V}(\mathrm{aOR}=1.37,95 \% \mathrm{Cl}=1.05-1.79)$ (Table 3$)$.

Table 3

Multiple Logistic Regression Analysis of the Association of Symptom with Performing Exercise and Consumption of Fruits and Vegetables (F\&V).

\begin{tabular}{|c|c|c|}
\hline Rank & Symptoms & Mean (SD) \\
\hline 1 & Fatigue & $4.0(2.5)$ \\
\hline 2 & Muscle cramps & $3.2(2.4)$ \\
\hline 3 & Decrease in memory & $2.7(2.3)$ \\
\hline 4 & Itching & $2.4(2.7)$ \\
\hline 5 & Dyspepsia & $2.4(2.3)$ \\
\hline 6 & Anorexia & $2.1(2.5)$ \\
\hline 7 & Dark urine & $2.0(2.3)$ \\
\hline 8 & Drowsiness & $1.8(2.2)$ \\
\hline 9 & Dry mouth & $1.8(2.2)$ \\
\hline 10 & Bruising & $1.6(2.1)$ \\
\hline 11 & RUQ pain & $1.5(2.1)$ \\
\hline 12 & SOB/dyspnea & $1.4(1.9)$ \\
\hline 13 & Nausea/vomiting & $1.3(1.9)$ \\
\hline 14 & Bodily pain & $1.3(2.0)$ \\
\hline 15 & Urinary difficulty & $1.1(1.8)$ \\
\hline 16 & Tarry stools & $1.1(1.9)$ \\
\hline 17 & Ascites/edema & $1.0(1.9)$ \\
\hline 18 & Change in appearance & $0.9(1.9)$ \\
\hline
\end{tabular}

\section{Factors Independently Associated with QOL}

Physical functioning was negatively associated with experiencing RUQ pain $\left(\beta=-3.69\right.$, partial $\left.\mathrm{R}^{2}=28 \%, p<.0001\right)$, muscle cramps $(\beta=-4.29$, partial $\left.\mathrm{R}^{2}=12 \%, p<.0001\right)$, itching $\left(\beta=-2.28\right.$, partial $\left.\mathrm{R}^{2}=5 \%, p=0.006\right)$, ascites/edema $\left(\beta=-2.98\right.$, partial $\left.\mathrm{R}^{2}=3 \%, p=0.025\right)$, bruising $(\beta=$ -2.44 , partial $\left.\mathrm{R}^{2}=3 \%, p=0.034\right)$, and anorexia $\left(\beta=-1.67\right.$, partial $\left.\mathrm{R}^{2}=2 \%, p=0.049\right)$. The linear model with these independent variables explained $53 \%$ of total variance in physical functioning.

Social functioning was negatively associated with experiencing body pain $\left(\beta=-5.55\right.$, partial $\left.\mathrm{R}^{2}=43 \%, p<.0001\right)$ and anorexia $(\beta=-1.58$, partial $\left.\mathrm{R}^{2}=3 \%, p=0.033\right)$, and positively associated with being employed $\left(\beta=10.30\right.$, partial $\left.\mathrm{R}^{2}=6 \%, p=0.003\right)$. The linear model with these independent variables explained $52 \%$ of the total variance in social functioning.

Role limitations due to physical health problems was positively associated with experiencing muscle cramps $\left(\beta=4.32\right.$, partial $\mathrm{R}^{2}=24 \%, p$ $<.0001)$ and anorexia $\left(\beta=4.42\right.$, partial $\left.\mathrm{R}^{2}=7 \%, p=0.004\right)$, and negatively associated with being married $\left(\beta=-19.86\right.$, partial $\mathrm{R}^{2}=6 \%, p=$ 
0.004). The linear model with these independent variables explained $37 \%$ of the total variance in role limitations resulting from physical health problems.

Role limitations due to emotional problems was positively associated with experiencing muscle cramps $\left(\beta=7.18\right.$, partial $\left.\mathrm{R}^{2}=26 \%, p<.0001\right)$ and change in appearance $\left(\beta=5.25\right.$, partial $\left.\mathrm{R}^{2}=26 \%, p=0.005\right)$. The linear model with these independent variables explained $52 \%$ of total variance in role limitations resulting from emotional problems (Table 4).

\section{Discussion}

The main findings of this study indicated that experiencing SOB was associated with a reduction in exercise; experiencing nausea and vomiting was associated with adopting exercise, and experiencing RUQ pain was associated with consuming F\&V. In addition, the QOL of LC patients was negatively affected by experiencing muscle cramps, anorexia, RUQ pain and body pain, itching, ascites or edema, bruising, and change in appearance. Our results suggest that the types of symptoms experienced by a patient with LC affect the patient's adoption of exercise, dietary behavior, and QOL.

The current study indicated that experiencing SOB was associated with a decrease in exercise performance. SOB can be complicated by ascites or pleural effusion in patients with cirrhosis. Dyspnea is well-known to induce exercise intolerance and individuals with daily-life dyspnea have more limited exercise capacity [19]. SOB may have inhibited exercise in cirrhosis population because this symptom becomes worse during exercise. Patients who perceive a temporary worsening of symptoms during physical activity may be less physically active [20]. Previous studies of the relationship between dyspnea and exercise intolerance were conducted in patients with pulmonary disease and multiple sclerosis. Therefore, further study is required to determine the impact of SOB on exercise levels in LC patients.

On the other hand, we found that experiencing nausea correlated with engaging in exercise and experiencing RUQ pain correlated with greater F\&V consumption. According to the Health Belief Model, patients will perform healthy behaviors if they believe there is a high risk that the symptoms and complications could adversely affect their lives, and that the performance of healthy behaviors is an effective method to these symptoms. When symptoms and complications are already present, this may prompt patients to adopt healthy behaviors. The positive association between development of nausea and performing exercise may be because exercise can induce gastrointestinal symptoms, such as nausea, heartburn, and abdominal pain [21]. This is because exercise can increase the level of catecholamine, which activates adrenergic receptors and induces nausea and vomiting [22]. In contrast, most longitudinal studies of patients with cancer have reported that those who exercise experienced significantly less intense nausea and greater alleviation of other symptoms [23]. The current study had a cross-sectional design, so we cannot determine whether nausea led to increased exercise or if increased exercise led to nausea. However, it is unlikely that patients with LC would exercise so intensely as to cause gastrointestinal symptoms. Thus, we believe that the experience of gastrointestinal symptoms has been a cue that increased the performance of exercise, according to the Health Belief Model. Further longitudinal studies are required to make a definitive conclusion on the causal relationship between symptom and the adoption of healthy behaviors.

Our results indicated that symptoms that were more frequent, intense, and distressing, differed from the symptoms that affected QOL. In particular, patients whose symptoms were more frequent, intensive, and distressing experienced fatigue, muscle cramps, and decreased memory, respectively. The findings are in line with those of a previous integrative review, which reported that fatigue was common among populations with chronic liver disease [24]. The general findings from the current study, which found an association of symptoms with poor QOL in patients with LC, agree with the findings of previous studies [25].

Experiencing muscle cramps can negatively influence physical functioning and increase role limitations. Patients with LC frequently report painful muscle cramps [26], and typically describe them as abrupt, uncomfortable squeezing or contraction of a muscle, that last seconds to minutes. Our finding supports a previous study, which reported that although muscle cramps are not life-threatening, they are a major concern and closely associated with perception of a poor health status perception among patients with LC [27]. Another previous study also showed that muscle cramps are related with significantly decreased QOL in patients with LC [28]. Because muscle cramps are often intermittent and subjective, and predisposition to cramping is difficult to measure using a diagnostic tool, clinicians and researchers often overlook this symptom [28]. Although muscle cramps are easy to ignore, they can significantly impact the QOL of patients with LC, so professional clinical nurses should help in the assessment of this symptom.

Experiencing anorexia can negatively impact physical and social functioning and increase role limitations. The finding was consistent with previous studies, which reported that patients with LC and gastrointestinal symptoms had profound reductions in physical functioning based on the SF-36 [29], and that malnutrition due to anorexia was significantly associated with self-perception of lower QOL in patients with LC [30]. 
RUQ pain and body pain can also negatively impact physical and social functioning. Our rating of symptoms according to their frequency, intensity, and distress indicated that RUQ pain ranked eleventh and body pain ranked fourteenth among all symptoms. Although pain is not among the most serious symptoms, a small change in patients' pain experience may significantly impact QOL, so it is important that professional clinical nurses carefully assess each patient's individual experience of pain. This finding supports a previous study that compared age and gender-matched controls and found that patients with LC were impaired in all QOL domain scores [27].

Itching and ascites/edema had a negative impact on physical functioning. Pruritus is an extrahepatic symptom that is the greatest burden for patients with LC, and our study rated it as the fourth-most serious symptom overall. Persistent itching may lead to severe sleep loss, depression, and suicidal thoughts in patients with LC [31]. Assessment of itching severity allows objective assessment of its influence on a patient's health and QOL, so that different therapies can be implemented. According to previous studies, ascites, serum sodium levels, and lower extremity edema were independently associated with impaired physical functioning [32] and decreased QOL in patients with LC [33]. Thus, professional clinical nurses should perform systematic assessments of patients with LC who present with itching, ascites, and edema.

Role limitations due to emotional problems were greater in those who experienced changes in appearance. We speculate that a patient with LC who has readily visible symptoms (itching, edema, and ascites) may experience greater problems with body self-image and consequently greater emotional distress. Previous clinical studies of patients with cancer reported that changes in physical appearance that resulted from disease progression or treatment produce psychological distress [34,35]. The development of changes in appearance can have a profound impact on multiple functions such as working with others [36]. The present study of patients with LC indicated that emotional problems due to a poor body self-image seemed to be associated with greater role limitations. Healthcare professionals should be aware of a patient's body self-image as a potential indicator of poor role functioning when referring a patient with LC for psychosocial care.

Being employed was positively associated with social functioning [37], and being married was negatively associated with role limitations [38]. These results are in line with the common idea that a patient who is married or in a common-law relationship has better health-related QOL. Previous studies also found that socioeconomic factors affected QOL, in those patients with HCV who were married or had a cohabitant had significantly better QOL than their single counterparts [39]. This is presumably because a spouse can provide social and emotional support that increases QOL.

This study indicated that symptoms had an impact QOL, yet performing exercise and consuming F\&V did not. Although some studies have reported exercise-induced improvement in the metabolic profile [40], a randomized controlled trial on home-based physical activity and diet intervention showed no improvement in QOL [41]. Thus, more evidence addressing the benefits of exercise and diet in relation to cirrhosis is still needed, with emphasis on individuals with cardiovascular risk, musculoskeletal disorders, and complications related to cirrhosis. Cirrhosis patients need certified exercise and diet professionals who can perform a detailed functional assessment and design an individualized exercise and diet regimen in order to improve their QOL [6].

The symptom scores of our patients were lower than in previous studies [15], possibly because the symptoms of patients with LC may be a wide range of symptom development in those with advanced disease, whereas patients with LC may be asymptomatic for years. Importantly, professional clinical nurses should keep in mind that although a symptom score may be low, the symptoms may still negatively affect QOL and health-related behaviors.

Clinical nurses play pivotal roles in the systematic assessment of symptoms and the implementation of treatments in the management of patients with LC. Identification of symptoms that occur during the different stages of LC may inform the development of interventions that target multiple symptoms at once, thereby improving the effectiveness of symptom management. Knowledge of the impact of symptom on QOL during the different stages of LC can guide best practices for symptom assessment. Our findings suggest that professional clinical nurses require a deep understanding of the symptoms of patients with LC.

The major limitations of this study are the use of cross-sectional design and the small sample size. However, because many previous studies of this topic also examined about 100 individuals, we believe it is reasonable to compare our results with those of previous studies. In addition, our results suggest that the adoption of healthy behaviors had no significant effect on QOL. Therefore, further longitudinal or experimental studies for patients with LC are required to identify the causal relationship between the adoption of healthy behaviors and QOL. Despite these limitations, very few previous studies have identified the various types of symptom and QOL in patients with LC.

In conclusion, this study of patients with LC indicated that the type of symptoms experienced by a patient can lead to the adoption or rejection of healthy behaviors and that the symptom of a patient can also negatively impact QOL. Patients with LC have symptom that differ in frequency, intensity, and distress, and that have different effects on QOL. Professional clinical nurses should carefully assess patients who have symptoms of anorexia, RUQ pain and body pain, ascites/edema, and change of appearance because these can negatively impact QOL, even in patients who appear to be asymptomatic. Patients with LC require specialized support for the assessment and management of 
symptoms. Identification of the association of symptom with the intention of adopting healthy behaviors and QOL provides a basis for the development of symptom management strategies and other interventions that may improve the QOL of patients with LC.

\section{Abbreviations}

LC: liver cirrhosis; F\&V: fruits and vegetables; QOL: quality of life; TTM: the transtheoretical model; RUQ: right upper quadrant; SOB: shortness of breath; SF-36: Short-Form Health Survey-36; aOR: adjusted odds ratio; Cl: confidence intervals; SD: standard deviation; M: mean

\section{Declarations}

\section{Funding}

This research was supported by the Basic Science Research Program through the National Research Foundation of Korea (NRF), funded by the Ministry of Science, ICT \& Future Planning (NRF-2014R1A1A1006809) for study design and data collection, and the National Research Foundation funded by the Korean government (Ministry of Science and ICT) (No. 2020R1F1A1057423) for data analysis and interpretation, writing of the manuscript and the decision to submit the manuscript for publication.

Acknowledgements The authors would like to thanks all the participants for their time.

Ethics approval and consent to participate This study was conducted in accordance with the Declaration of Helsinki, and the study protocol was reviewed and approved by the Institutional Review Board of the Keimyung University Daegu Dongsan Hospital (2015-09-020-003) and Kyungpook National University (2015-87). Informed consent information was included with each questionnaire and introduced before the surveys. Surveys were only conducted if participants were fully informed of the content and aim of this research project and agreed to participate.

Consent for publication Not applicable.

Availability of data and materials The data sets generated during and/or analyzed during the current study are available from the corresponding authors on reasonable request.

Competing interests The authors declare that they have no competing interests.

Funding This research was supported by the Basic Science Research Program through the National Research Foundation of Korea (NRF), funded by the Ministry of Science, ICT \& Future Planning (NRF-2014R1A1A1006809) for study design and data collection, and the National Research Foundation funded by the Korean government (Ministry of Science and ICT) (No. 2020R1F1A1057423) for data analysis and interpretation, writing of the manuscript and the decision to submit the manuscript for publication.

\section{Authors' contributions}

All authors have read and approved the manuscript.

\section{References}

1. World Health Organization. Global Hepatitis Report. 2017.

2. Wittmer VL, Lima RT, Maia MC, Duarte H, Paro FM. Respiratory and symptomatic impact of ascitis relief by paracentesis in patients with hepatic cirrhosis. Arq Gastroenterol. 2020;57:64-8.

3. Alavinejad P, Hajiani E, Danyaee B, Morvaridi M. The effect of nutritional education and continuous monitoring on clinical symptoms, knowledge, and quality of life in patients with cirrhosis. Gastroenterol Hepatol Bed Bench. 2019;12:17-24.

4. Macdonald S, Jepsen P, Alrubaiy L, Watson H, Vilstrup H, Jalan R. Quality of life measures predict mortality in patients with cirrhosis and severe ascites. Aliment Pharmacol Ther. 2019;49:321-30.

5. Les I, Doval E, Flavia M, Jacas C, Cardenas G, Esteban R, Guardia J, Cordoba J. Quality of life in cirrhosis is related to potentially treatable factors. Eur J Gastroenterol Hepatol. 2010;22:221-7.

6. Tandon P, Ismond KP, Riess K, Duarte-Rojo A, Al-Judaibi B, Dunn MA, Holman J, Howes N, Haykowsky MJF, Josbeno DA, McNeely M. Exercise in cirrhosis: Translating evidence and experience to practice. $J$ Hepatol 2018.

7. Barnes RY, Jelsma J, Parker R. Improvements in health-related quality of life and function in middle-aged women with chronic diseases of lifestyle after participating in a non-pharmacological intervention programme: A pragmatic randomised controlled trial. Afr $\mathrm{J}$ Disabil. 
2019;8:428.

8. Chen HW, Dunn MA. Arresting frailty and sarcopenia in cirrhosis: Future prospects. Clinical Liver Disease. 2018;11:52-7.

9. Macias-Rodriguez RU, Ruiz-Margain A, Roman-Calleja BM, Moreno-Tavarez E, Weber-Sangri L, Gonzalez-Arellano MF, Fernandez-DelRivero G, Ramirez-Soto K. Exercise prescription in patients with cirrhosis: Recommendations for clinical practice. Rev Gastroenterol Mex. 2019;84:326-43.

10. Buscail C, Bourcier V, Fezeu LK, Roulot D, Brule S, Ben-Abdesselam Z, Cagnot C, Hercberg S, Nahon P, Ganne-Carrie N, Julia C. Eating Patterns in Patients with Compensated Cirrhosis: A Case-Control Study. Nutrients 2018, 10.

11. Jones JC, Coombes JS, Macdonald GA. Exercise capacity and muscle strength in patients with cirrhosis. Liver Transpl. 2012;18:14651.

12. Gundling F, Seidl H, Pehl C, Schmidt T, Schepp W. How close do gastroenterologists follow specific guidelines for nutrition recommendations in liver cirrhosis? A survey of current practice. Eur J Gastroenterol Hepatol. 2009;21:756-61.

13. Campollo O, Sprengers D, Dam G, Vilstrup H, Mclntyre N. Protein tolerance to standard and high protein meals in patients with liver cirrhosis. World J Hepatol. 2017;9:667-76.

14. Prochaska JO, Velicer WF. The transtheoretical model of health behavior change. American journal of health promotion. 1997;12:38-48.

15. Kim SH, Oh EG, Lee WH. Symptom experience, psychological distress, and quality of life in Korean patients with liver cirrhosis: a crosssectional survey. Int J Nurs Stud. 2006;43:1047-56.

16. Briggs Early K, Armstrong Shultz J, Evans M, Corbett CF, Nicholson Butkus S, Massey L. Dietary goal attainment measures and psychosocial factors among Mexican Americans and non-Hispanic whites with type 2 diabetes. Ecol Food Nutr. 2012;51:227-46.

17. Brown JK, Byers T, Doyle C, Coumeya KS, Demark-Wahnefried W, Kushi LH, McTieman A, Rock CL, Aziz N, Bloch AS, et al. Nutrition and physical activity during and after cancer treatment: an American Cancer Society guide for informed choices. CA Cancer J Clin. 2003;53:268-91.

18. Kim SH, Jo MW, Lee SI. Psychometric properties of the Korean short form-36 health survey version 2 for assessing the general population. Asian Nurs Res (Korean Soc Nurs Sci). 2013;7:61-6.

19. Rocha A, Arbex FF, Sperandio PA, Souza A, Biazzim L, Mancuso F, Berton DC, Hochhegger B, Alencar MCN, Nery LE, et al. Excess Ventilation in Chronic Obstructive Pulmonary Disease-Heart Failure Overlap. Implications for Dyspnea and Exercise Intolerance. Am J Respir Crit Care Med. 2017;196:1264-74.

20. Moumdjian L, Gervasoni E, Van Halewyck F, Wens BOE, Van Geel I, Van Wijmeersch F, Feys B, Van Asch P. P: Walking endurance and perceived symptom severity after a single maximal exercise test in persons with mild disability because of multiple sclerosis. Int $J$ Rehabil Res 2018.

21. Kondo T, Nakae Y, Mitsui T, Kagaya M, Matsutani Y, Horibe H, Read NW. Exercise-induced nausea is exaggerated by eating. Appetite. 2001;36:119-25.

22. King KS, Darmani NA, Hughes MS, Adams KT, Pacak K. Exercise-induced nausea and vomiting: another sign and symptom of pheochromocytoma and paraganglioma. Endocrine. 2010;37:403-7.

23. Lee J, Dodd MJ, Dibble SL, Abrams DI. Nausea at the end of adjuvant cancer treatment in relation to exercise during treatment in patients with breast cancer. Oncol Nurs Forum. 2008;35:830-5.

24. Jopson L, Jones DE. Fatigue in Primary Biliary Cirrhosis: Prevalence, Pathogenesis and Management. Dig Dis. 2015;33(Suppl 2):10914.

25. Huang R, Rao H, Shang J, Chen H, Li J, Xie Q, Gao Z, Wang L, Wei J, Jiang J, et al. A cross-sectional assessment of health-related quality of life in Chinese patients with chronic hepatitis c virus infection with EQ-5D. Health Qual Life Outcomes. 2018;16:124.

26. Konikoff F, Theodor E. Painful muscle cramps. A symptom of liver cirrhosis? J Clin Gastroenterol. 1986;8:669-72.

27. Marchesini G, Bianchi G, Amodio P, Salerno F, Merli M, Panella C, Loguercio C, Apolone G, Niero M, Abbiati R. Factors associated with poor health-related quality of life of patients with cirrhosis. Gastroenterology. 2001;120:170-8.

28. Chatrath $\mathrm{H}$, Liangpunsakul S, Ghabril M, Otte J, Chalasani N, Vuppalanchi R. Prevalence and morbidity associated with muscle cramps in patients with cirrhosis. Am J Med. 2012;125:1019-25.

29. Kalaitzakis E, Simren M, Olsson R, Henfridsson P, Hugosson I, Bengtsson M, Bjornsson E. Gastrointestinal symptoms in patients with liver cirrhosis: associations with nutritional status and health-related quality of life. Scand J Gastroenterol. 2006;41:1464-72.

30. Rojas-Loureiro G, Servin-Caamano A, Perez-Reyes E, Servin-Abad L, Higuera-de la Tijera F. Malnutrition negatively impacts the quality of life of patients with cirrhosis: An observational study. World J Hepatol. 2017;9:263-9. 
31. Hegade VS, Bolier R, Oude Elferink RP, Beuers U, Kendrick S, Jones DE. A systematic approach to the management of cholestatic pruritus in primary biliary cirrhosis. Frontline Gastroenterol. 2016;7:158-66.

32. Sola E, Watson H, Graupera I, Turon F, Barreto R, Rodriguez E, Pavesi M, Arroyo V, Guevara M, Gines P. Factors related to quality of life in patients with cirrhosis and ascites: relevance of serum sodium concentration and leg edema. J Hepatol. 2012;57:1199-206.

33. European Association for the Study of the Liver. EASL clinical practice guidelines on the management of ascites, spontaneous bacterial peritonitis, and hepatorenal syndrome in cirrhosis. J Hepatol. 2010;53:397-417.

34. Galiano-Castillo N, Ariza-Garcia A, Cantarero-Villanueva I, Fernandez-Lao C, Diaz-Rodriguez L, Arroyo-Morales M. Depressed mood in breast cancer survivors: associations with physical activity, cancer-related fatigue, quality of life, and fitness level. Eur $\mathrm{J}$ Oncol Nurs. 2014;18:206-10.

35. Reese JB, Handorf E, Haythornthwaite JA. Sexual quality of life, body image distress, and psychosocial outcomes in colorectal cancer: a longitudinal study. Support Care Cancer. 2018;26:3431-40.

36. Lee MK, Kang HS, Lee KS, Lee ES. Three-Year Prospective Cohort Study of Factors Associated with Return to Work After Breast Cancer Diagnosis. J Occup Rehabil. 2017;27:547-58.

37. Stepanova M, De Avila L, Afendy M, Younossi I, Pham H, Cable R, Younossi ZM. Direct and Indirect Economic Burden of Chronic Liver Disease in the United States. Clin Gastroenterol Hepatol. 2017;15:759-66.e755.

38. Hsu PC, Federico CA, Krajden M, Yoshida EM, Bremner KE, Anderson FH, Weiss AA, Krahn MD. Health utilities and psychometric quality of life in patients with early- and late-stage hepatitis C virus infection. J Gastroenterol Hepatol. 2012;27:149-57.

39. Gjeruldsen S, Loge JH, Myrvang B, Opjordsmoen S. Drug addiction in hepatitis C patients leads to a lower quality of life. Nord J Psychiatry. 2006;60:157-61.

40. Naseer M, Turse EP, Syed A, Dailey FE, Zatreh M, Tahan V. Interventions to improve sarcopenia in cirrhosis: A systematic review. World J Clin Cases. 2019;7:156-70.

41. Chen HW, Ferrando A, White MG, Dennis RA, Xie J, Pauly M, Park S, Bartter T, Dunn MA, Ruiz-Margain A, et al: Home-Based Physical Activity and Diet Intervention to Improve Physical Function in Advanced Liver Disease: A Randomized Pilot Trial. Dig Dis Sci 2020. 